\title{
Evidence for the Efficacy of the Youth-Physical Activity towards Health (Y-PATH) Intervention
}

\author{
Wesley O’ Brien, Johann Issartel, Sarahjane Belton \\ School of Health and Human Performance, Dublin City University, Dublin, Ireland \\ Email: wesley.obrien5@mail.dcu.ie
}

Received July $9^{\text {th }}, 2013$; revised August $9^{\text {th }}, 2013$; accepted August $16^{\text {th }}, 2013$

\begin{abstract}
Copyright (C) 2013 Wesley O’ Brien et al. This is an open access article distributed under the Creative Commons Attribution License, which permits unrestricted use, distribution, and reproduction in any medium, provided the original work is properly cited.
\end{abstract}

\begin{abstract}
The physical education environment is a key opportunity to intervene because of access to children and adolescents for the purpose of increasing physical activity participation and improving fundamental movement skill proficiency. A non-randomised controlled trial involving two schools in a rural Irish town was carried out in September 2011 to evaluate the Youth-Physical Activity Towards Health (Y-PATH) intervention. Data were collected on 12 to 14 year olds $(n=174)$ at 3 time points (pre, post and retention). Data collected included measured height and weight, physical activity measured by accelerometry and by self-report and fundamental movement skill performance. Both the control and intervention school showed significant increases in daily physical activity and gross motor skill proficiency over time. Twoway repeated measures ANOVA showed a significant interaction effect between school attended and time for physical activity $(\mathrm{F}(2,38)=6.177, p=.005)$ and fundamental movement skills $(\mathrm{F}(2,100)=4.132, p$ $=.019$ ), with a significantly greater increase in physical activity and fundamental movement skills observed in the intervention school. Preliminary findings from this study suggest a positive effect for the Y-PATH intervention and provide support for its potential in increasing physical activity and fundamental movement skill levels of adolescent youth. Further research involving a definitive randomised controlled trial with a larger sample size is warranted.
\end{abstract}

Keywords: Physical Education; Adolescent; Physical Activity; Fundamental Movement Skills; Intervention

\section{Introduction}

Physical activity (PA) is a complex, multifaceted behavior which can be performed in a variety of physical and social settings, and for many reasons (Ward, Saunders, \& Pate, 2007). The meaning of PA has remained consistent among public health professionals in recent years and a standardized PA definition has become accepted as any bodily movement produced by the skeletal muscles expending energy beyond resting levels (Bouchard, Blair, \& Haskell, 2007; Caspersen, Powell, \& Christenson, 1985). Regular PA decreases numerous health risks for all age groups and is associated with a reduced risk of developing chronic disease such as coronary heart disease, type II diabetes, cancers and hypertension (Bouchard et al., 2007; Physical Activity Guidelines Advisory Committee, 2008). In the past, the development of these chronic diseases has been rare in children (Physical Activity Guidelines Advisory Committee, 2012) but a growing body of literature is now showing that the prevalence of these risk factors is increasing among adolescents (May, Kuklina, \& Yoon, 2012; Woods, Tannehill, Quinlan, Moyna, \& Walsh, 2010).

Whilst the knowledge about the tracking of PA is limited (Telama, 2009), some studies have shown that the engagement of children and adolescents in regular PA significantly predicts PA participation during adulthood (Telama et al., 2005; Wichstrøm, von Soest, \& Kvalem, 2012). Despite the known impor- tance of regular PA participation in the promotion of lifelong health and well-being (Physical Activity Guidelines Advisory Committee, 2012), current evidence suggests that the levels of PA participation among children remain low, particularly noting that the age related decline occurs dramatically during adolescence (Aibar, Bois, Generelo, Zaragoza Casterad, \& Paillard, 2012; Grasten, Watt, Jaakkola, \& Liukkonen, 2012; Kimm et al., 2000; O' Donovan et al., 2010). Irish research from the "Children's Sport Participation and Physical Activity Study" (CSPPA) found that only $12 \%$ of adolescents aged between 12 to 18 years old met the recommended 60 minutes per day PA guideline (Woods et al., 2010). Compared to Irish adolescents, recent research in the US (Eaton et al., 2012) found that a higher percentage of adolescents (29\%) achieved this recommended guideline. The prevalence of PA among Irish adolescents is also very low when compared in a European context with $35.9 \%$ of adolescents in France and Spain reported to meet the 60 minute guideline (Aibar et al., 2012). Many interventions have been evaluated for their effectiveness in increasing the PA levels of adolescents (Haerens, De Bourdeaudhuij, Maes, Cardon, \& Deforche, 2007; Kalaja, Jaakkola, Liukkonen, \& Digelidis, 2012; McKenzie et al., 2004; Pate et al., 2005).

Recent research, underpinning the necessity of an active lifestyle, suggests that fundamental movement skills (FMS) are the building blocks for movement as they provide the foundation for the acquisition of more complex skills in the specialized 
sport specific movement stage (Gallahue \& Ozmun, 2006; Hardy, King, Espinel, Cosgrove, \& Bauman, 2010). Furthermore, the rationale for promoting the development of FMS in childhood relies on the recent findings from a systematic review (Lubans, Morgan, Cliff, Barnett, \& Okely, 2010) of the current and future benefits associated with the acquisition of FMS in children and adolescents. This systematic review (Lubans et al., 2010) found a relationship between FMS competency and eight potential benefits, namely global self-concept, perceived physical competence, cardio-respiratory fitness (CRF), muscular fitness, weight status, flexibility, PA and reduced sedentary behavior. While in recent years, adolescent PA levels have shown some correlation with FMS proficiency (Barnett, Morgan, Van Beurden, Ball, \& Lubans, 2011; Barnett, Van Beurden, Morgan, Brooks, \& Beard, 2009; Okely, Booth, \& Patterson, 2001), further longitudinal research examining their relationship is recommended (Lubans et al., 2010).

Despite the associated physiological, psychological and behavioral outcomes for FMS proficiency and their positive impact on public health, it is apparent that a lot of children do not acquire these basic patterns of movement. There is now strong evidence that early adolescents have low levels of FMS proficiency (Booth et al., 1999; Hardy et al., 2010, 2013; Mitchell et al., 2013). A previously successful intervention among primary school children, "Move it Groove it" (Van Beurden et al., 2003), provided school aged youth with opportunities to incorporate PA into their daily life while simultaneously targeting FMS. Other school-based intervention studies, in more recent years have also shown positive effects for FMS provision during childhood (Lemos, Avigo, \& Barela, 2012; Mitchell et al., 2013; Zask et al., 2012). Yet, there appears to be a dearth of FMS intervention research among adolescents, therefore, addressing both PA and FMS may be perceived as a practical intervention approach for the journey into sport and exercise skill development (Woods et al., 2010).

In terms of increasing active adolescent behavior, the school environment has the potential to make important differences to PA participation and presents a number of opportunities for intervention (Garn, McCaughtry, Shen, Martin, \& Fahlman, 2013; Lavelle, Mackay, \& Pell, 2012; Van Sluijs, McMinn, \& Griffin, 2008; Vasques et al., 2013; Ward et al., 2007). A recent report by Sallis et al., (2012) highlighted that in the past two decades, evidence-based school curricula have shown significant differences in moderate to vigorous physical activity (MVPA) during and outside of school hours. The school environment presents many opportunities for targeting the adolescent directly with many studies suggesting the importance of targeting ecological domains beyond the individual (Kahn et al., 2002; Perry, Garside, Morones, \& Hayman, 2012; Sallis et al., 2012). Effective school environments present opportunities to embody a culture of care, and to be fully inclusive of the individual regardless of the existing racial or socio economic background differences (Cavanagh, Macfarlane, Glynn, \& Macfarlane, 2012). The development of evidence-based school programmes has seen the acceptance of Physical Education (PE) as an efficacious resource (Sallis et al., 2012).

As a viable change agent to increase PA in the school-aged population, PE is considered a very important provider of PA (McKenzie \& Lounsbery, 2009; Payne \& Morrow, 2009; Scheerder et al., 2008; Ward et al., 2007). PE also gives children and adolescent youth an opportunity to learn physical and behavioral movement skills (Haerens et al., 2007; Lemos et al.,
2012; McKenzie \& Lounsbery, 2009; Mitchell et al., 2013; Van Beurden et al., 2003). A recent meta-analysis of the effectiveness of motor skill interventions illustrates a significantly positive association between participation in school-based motor skill programmes and FMS proficiency (Logan, Robinson, Wilson, \& Lucas, 2011). Recent intervention programmes such as "Move it Groove it" (MIGI) and "Project Energize" highlighted that both PA and FMS can be integrated during the provision of PE (Mitchell et al., 2013; Van Beurden et al., 2003).

The purpose of this paper was to evaluate the intervention effect after 9 months (end of academic school year) and 12 months (follow-up) of a tailored PA and FMS programme for an Irish adolescent cohort (12 - 14 years of age). The Y-PATH intervention is an innovative whole school approach to activity promotion among adolescents; there is a specific gap in the literature among adolescents as no previous study to this researcher's knowledge has examined the effect of a prescribed Health Related Activity (HRA) and FMS intervention on PA levels and its impact on public health. The study involved one intervention group who received the Youth-Physical Activity Towards Health (Y-PATH) intervention over the course of one school year, and one control group who received their usual PE programme for the same period. The main research question was to examine if the intervention group would demonstrate a significant increase in minutes of daily PA and levels of FMS proficiency over time when compared to the control group. Standard anthropometric characteristics (height and weight) were also measured over time between both groups to see if body mass index (BMI) was having any underlying effect on the intervention.

\section{Methods}

\section{Participants and Recruitment}

This quasi-experimental non-randomised controlled trial is part of the Y-PATH research programme which was initiated in September 2010 at Dublin City University (DCU). Following the Medical Research Council (MRC) guidelines (2000) for developing and evaluating a tailored intervention, this research represented Phase 2 on the continuum of increasing evidence; the exploratory trial. Non-randomised controlled trials can detect associations between the intervention and the outcome (Sibbald \& Roland, 1998).

For this pilot study (2011-2012), a convenience sample of Irish adolescents enrolled in year one of post-primary education (12 - 14 years of age) from two mixed-gender schools were invited to take part in the study $(\mathrm{N}=192)$. Both schools involved in this research study were from the same rural Irish town, had no school fee paying requirements (public), and were not listed as "Designated Disadvantaged" schools by the Department of Education and Skills. The school with the largest sample size $(n=132)$ was randomly selected to receive the intervention for one academic school (with the agreement that all intervention resources would be made available to the control school in October 2012, following the completion of data collection). Data collected included measured height and weight, PA measured by accelerometry and by self-report and FMS performance. Approval from each of the principals of the two participating schools was granted. Informed consent for participation was sought from each adolescent and their parent/ 
guardian. Ethical approval was obtained from the Dublin City University Research Ethics Committee.

\section{The Y-PATH Intervention}

There are four key components to the Y-PATH intervention 1) Student component: Specific focus on HRA and FMS content subsumed within the existing PE curriculum, delivered by specialist PE teachers. 2) Parent/Guardian component: PA information evening prior to the beginning of the intervention, and distribution of specifically tailored Y-PATH PA information leaflets. 3) Teacher component: All school teachers attending two workshops (Aug 2011 and Jan 2012) which highlighted the importance of "active role modeling", and voluntary participation in a one week "Teacher Pedometer Challenge". The teacher pedometer challenge was integrated mid-course during the Y-PATH intervention to further stimulate teacher involvement in youth PA promotion (teacher pedometer data, however, was not collected as part of this pilot Y-PATH exploratory trial). 4) Website component: All student, parent and teacher resources were made readily available for all intervention participants (http://www.dcu.ie/shhp/y_path.shtml). It is important to note that those in the control condition carried on their usual PE and school programme without any researcher input during the pilot study.

\section{Measurements}

Measurements were taken at the beginning of the school year in September 2011 (pre), at the end of the school year in May 2012 (post), and at 3 months follow-up in September 2012 (retention). Three lead researchers administered periodic training workshops to 12 field staff to ensure that measurement assessment standards were met continuously during data collection (Berkson et al., 2013).

Body Mass Index: Weight was measured to the nearest $.1 \mathrm{~kg}$ using the Seca 761 dual platform weighing scales. Standing height was measured to the nearest $.1 \mathrm{~cm}$ using a portable stadiometer. BMI was calculated using the equation; weight $(\mathrm{kg}) /$ height $\left(\mathrm{m}^{2}\right)$. The Cole et al., (2000) cut off points for normal, overweight and obese participants were applied to the data in order to calculate BMI class.

Accelerometry: PA was measured using ActiGraph GT1M and GT3X accelerometers, stored in a standardized 10-second epoch to capture the intermittent and sporadic behavior (Esliger, Copeland, Barnes, \& Tremblay, 2005) of adolescent youth. During the first day of data collection, each participant was given an accelerometer by one of the trained field staff under the supervision of one lead researcher. If a participant felt that the device was uncomfortable, the elastic belt was adjusted accordingly to ensure secure fit. This process ensured that participants could wear the accelerometer independently for the subsequent days of data collection. To further enhance accelerometer compliance, a reminder text message was sent each morning which has been shown to improve the number of students wearing monitors to school (Belton et al., 2013). Each participant was asked to wear an accelerometer during all waking hours for nine consecutive days. To account for subject reactivity where participants may artificially increase their activity with the device, the first day of data was omitted from the analysis (Esliger et al., 2005).

Accelerometer data gathered was screened using stringent inclusion criteria of a minimum of three weekdays and one weekend day (Gorely, Nevill, Morris, Stensel, \& Nevill, 2009; Nyberg, Ekelund, \& Marcus, 2009) with 600 minutes wear time per day (Anderson, Hagstromer, \& Yngve, 2005). Strings of " 0 " counts in bouts of $\geq 20$ min were considered non-wear periods (Yildirim et al., 2011), and activity count values of $<0$ and $\geq 15,000$ counts per minute were excluded as these values were deemed biologically implausible (Esliger et al., 2005). The average time spent in daily MVPA was calculated by applying the Evenson age specific cutpoints (Evenson, Catellier, Gill, Ondrak, \& McMurray, 2008) to the Actilife 6.4 software data reduction programme.

Self-Report: PA was further measured using the Youth Physical Activity Questionnaire (YPAQ) self-report questionnaire which has been previously validated against accelerometry (concurrent validity coefficient $\mathrm{r}=.42, p<.05$ ) with 12 to 13 year olds (Corder et al., 2009). Reported test-retest reliability coefficients for the YPAQ ranged from .86 to .92 (Corder et al., 2009). The variable for daily minutes of MVPA was calculated by averaging the total summed minutes of MVPA across the 7 days. Participants completed the questionnaire within their class groups under the supervision of one lead researcher and four trained field staff members. If a participant was unsure of any questionnaire component or had difficulty completing the task, they were assisted upon request by one of the research team present. Participants completed questionnaires using the online tool "Survey Monkey".

Fundamental Movement Skills: The following 15 FMS were assessed: run, skip, gallop, slide, leap, hop, horizontal jump and vertical jump (locomotor; maximum score of 66); kick, catch, overhand throw, strike, underhand roll and stationary dribble (object control; maximum score of 48); balance (stability; maximum score of 10). Each of the 15 gross motor skills were assessed in conjunction with the guidelines from the Test of Gross Motor Development (TGMD), Test of Gross Motor Development-2 (TGMD-2) and the Victorian Fundamental Motor Skills manual (Department of Education Victoria, 1996; Ulrich, 1985, 2000). To ensure that adolescent performance was constant over time across the 15 selected FMS, trained field staff conducted a 48 hour time sampling test-retest reliability measurement amongst a sample of 35 participants aged 12 - 13 years old. The FMS coefficients reached .75 (locomotor subtest), .78 (object control subtest) and .91 (overall gross motor skill subtest), showing the scores across the range of FMS to be stable over time. During the data collection, one trained field staff member provided every 5 participants with an accurate demonstration and verbal description of the skill to be performed. To ensure participant consistency within skill performance, no feedback from any of the trained field staff were given during the testing. Participants performed the skill on 3 occasions including 1 familiarization practice and 2 performance trials. Video cameras were used to record each participant's performance and execution of the selected 15 FMS. The FMS scoring process was completed at a later date by the trained field staff. The trained field staff were required to reach a minimum of $95 \%$ inter-observer agreement for all 15 skills on a pre-coded data set.

\section{Data Analysis}

Data were analyzed using SPSS version 17.0 for Windows. Descriptive statistics and frequencies for the anthropometric 
characteristics, objective PA and self-report PA over time were calculated. Differences in BMI mean scores at pre, post and retention according to gender and school type were analyzed using two-way repeated measures ANOVA.

Chi-square tests for independence were used to identify from the self-report data whether percentage differences in meeting the $\geq 60$ minutes MVPA guideline according to school type existed at pre, post and retention. For FMS analysis, the binary variable "mastery and near mastery" (MNM) was created. "Mastery" was defined as correct performance of all skill components on both trials. "Near Mastery" was defined as correct performance of all components but one on both trials (Van Beurden et al., 2003). Pre, post and retention FMS scores were calculated for all 15 FMS and subtests for the intervention group relative to the control using independent t-tests.

Individual two-way repeated measures ANOVA were conducted to explore the impact of gender and school type (intervention group relative to control) over time (pre, post and retention) on objective daily MVPA minutes, self-report daily MVPA minutes, and FMS gross motor skill proficiency. Statistical significance was set at $p<.05$.

\section{Results}

\section{Study Sample}

One hundred and ninety two participants from two schools were invited to participate in this study in September 2011 with consent from 174 participants provided (91\% of total sample, $n$ $=119$ intervention, $\mathrm{n}=55$ control group). Of these 174 participants, only those who had full data sets available across all three time periods were included in the statistical analysis.

\section{Body Mass Index and Physical Activity}

BMI characteristics, objective PA and self-report PA descriptive statistics at pre, post and retention phases, for both the control and intervention groups, are summarized in Table 1. There were no significant differences between gender and school type for BMI across the three time periods.

\section{Accelerometer Physical Activity}

Based on the inclusion criteria applied to the accelerometer data, $23 \%$ of participants had fully available PA data across three time periods. There was a significant interaction between school and time for PA $(\mathrm{F}(2,38)=6.177, p=.005)$ with both schools showing an increase in daily MVPA over the three time periods, with a significantly greater increase in daily MVPA occurring within the intervention school.

\section{Self-Report Physical Activity}

Figure 1 illustrates the percentage of participants who accumulated $\geq 60$ minutes of MVPA each day according to the self-report data. There was no school type differences observed in the overall percentage accumulating the $\geq 60$ minutes MVPA guideline $(p>.05)$ according to self-reported data at pre, post or retention phases. When comparing self-reported minutes of daily MVPA according to school type (intervention, control) and gender over time (pre, post and retention), no significant interaction between school attended, gender and self-reported minutes of PA over time was found.
Table 1.

The anthropometric characteristics and mean (SD) values for average accelerometer and self report daily minutes of MVPA of Irish postprimary adolescent youth from 2011-2012 (pre, post and retention data collection phases) according to intervention and control condition.

\begin{tabular}{|c|c|c|c|}
\hline Time & BMI $\left(\mathrm{kg} / \mathrm{m}^{2}\right)$ & $\begin{array}{c}\text { Accelerometer } \\
\text { Daily MVPA }^{1}\end{array}$ & $\begin{array}{r}\text { Self-Report } \\
\text { Daily MVPA }\end{array}$ \\
\hline \multicolumn{4}{|l|}{ Pre } \\
\hline \multirow{2}{*}{ Intervention } & $(\mathrm{n}=103)$ & $(\mathrm{n}=61)$ & $(\mathrm{n}=70)$ \\
\hline & $20.36 \pm 3.38$ & $51.38 \pm 20.70^{*}$ & $85.17 \pm 66.00$ \\
\hline \multirow{2}{*}{ Control } & $(\mathrm{n}=51)$ & $(\mathrm{n}=34)$ & $(\mathrm{n}=49)$ \\
\hline & $20.35 \pm 3.26$ & $43.48 \pm 13.96^{*}$ & $91.78 \pm 55.70$ \\
\hline \multicolumn{4}{|l|}{ Post } \\
\hline \multirow{2}{*}{ Intervention } & $(\mathrm{n}=89)$ & $(\mathrm{n}=39)$ & $(\mathrm{n}=70)$ \\
\hline & $20.69 \pm 3.37$ & $47.76 \pm 17.72$ & $80.48 \pm 45.64$ \\
\hline \multirow{2}{*}{ Control } & $(n=46)$ & $(\mathrm{n}=36)$ & $(n=49)$ \\
\hline & $20.50 \pm 3.11$ & $55.20 \pm 20.52$ & $88.40 \pm 39.76$ \\
\hline \multicolumn{4}{|l|}{ Retention } \\
\hline \multirow{2}{*}{ Intervention } & $(\mathrm{n}=89)$ & $(\mathrm{n}=30)$ & $(\mathrm{n}=70)$ \\
\hline & $20.72 \pm 3.26$ & $59.17 \pm 19.33$ & $71.83 \pm 46.57^{* *}$ \\
\hline \multirow{2}{*}{ Control } & $(\mathrm{n}=51)$ & $(\mathrm{n}=34)$ & $(n=49)$ \\
\hline & $20.96 \pm 3.25$ & $51.95 \pm 17.89$ & $93.21 \pm 36.90^{* *}$ \\
\hline
\end{tabular}

Note: $\mathbf{n}=$ number of participants with available data. ${ }^{*}=p<.05 ;{ }^{* *}=p<.01$; MVPA $=$ moderate to vigorous physical activity; $\mathbf{B M I}=$ body mass index.

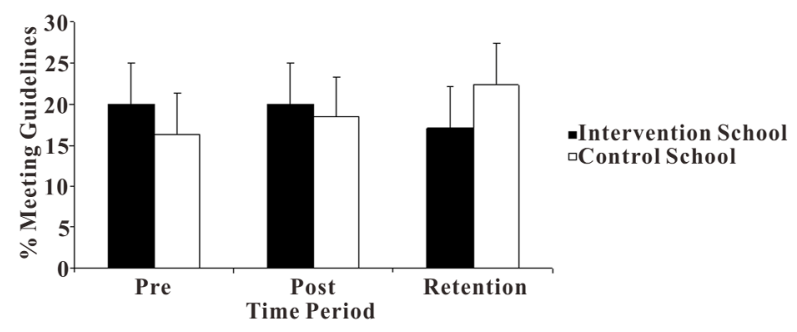

Figure 1.

Percentage of participants self-reporting $\geq 60$ minutes of MVPA on all 7 days per week at pre, post and retention.

\section{Fundamental Movement Skills}

The mean scores for each of the 15 FMS and the associated subtests at pre, post and retention phases, for both the control and intervention groups, are summarised in Table 2. At pre-test, school-specific profiles differed with the control group displaying significantly greater proficiency in the vertical jump $(p<.01)$, the object control subtest $(p<.05)$, and total gross motor skill proficiency $(p<.05)$.

There was a significant difference in improvement from pretest to retention test between both intervention and control condition for gross motor skill proficiency $(\mathrm{F}(2,100)=4.132$,

${ }^{1}$ Those who had available accelerometer data and met the inclusion criteria at each phase of data collection (pre, post and retention). 
Table 2.

FMS $(n=15)$ raw mean scores at pre, post and retention phases for intervention group relative to control.

\begin{tabular}{|c|c|c|c|c|c|c|}
\hline Skill/Condition & $\begin{array}{c}\text { Pre FMS } \\
\text { mean score }\end{array}$ & & $\begin{array}{c}\text { Post FMS } \\
\text { mean score }\end{array}$ & & $\begin{array}{c}\text { Retention FMS } \\
\text { mean score }\end{array}$ & \\
\hline \multicolumn{7}{|l|}{ Run (max score 8) } \\
\hline Intervention & 7.69 & & 7.63 & & 7.77 & \\
\hline Control & 7.71 & & 7.66 & & 7.68 & \\
\hline \multicolumn{7}{|l|}{ Gallop (max score 8) } \\
\hline Intervention & 6.45 & & 6.41 & & 6.78 & \\
\hline Control & 6.29 & & 6.92 & & 6.71 & \\
\hline \multicolumn{7}{|l|}{ Hop (max score 10) } \\
\hline Intervention & 8.48 & & 8.55 & & 9.59 & \\
\hline Control & 8.66 & & 8.12 & & 9.37 & \\
\hline \multicolumn{7}{|l|}{ Slide (max score 8) } \\
\hline Intervention & 6.71 & & 6.84 & & 7.39 & \\
\hline Control & 6.58 & & 7.08 & & 6.97 & \\
\hline \multicolumn{7}{|l|}{ Leap (max score 6) } \\
\hline Intervention & 3.67 & & 4.27 & & 4.63 & \\
\hline Control & 4.03 & & 4.53 & & 4.42 & \\
\hline \multicolumn{7}{|l|}{ Vertical Jump (max score 12) } \\
\hline Intervention & 9.09 & \multirow{2}{*}{$p<.01^{* *}$} & 10.13 & & 10.62 & \multirow{2}{*}{$p<.01^{* *}$} \\
\hline Control & 10.32 & & 10.63 & & 11.39 & \\
\hline \multicolumn{7}{|l|}{ Horizontal Jump (max score 8) } \\
\hline Intervention & 3.94 & & 5.61 & & 6.53 & \\
\hline Control & 4.45 & & 5.55 & & 6.51 & \\
\hline \multicolumn{7}{|l|}{ Skip (max score 6) } \\
\hline Intervention & 5.03 & & 5.48 & & 5.21 & \\
\hline Control & 5.18 & & 5.32 & & 5.26 & \\
\hline \multicolumn{7}{|c|}{ Locomotor Subtest Total (max score 66) } \\
\hline Intervention & 51.06 & & 54.91 & & 58.52 & \\
\hline Control & 53.21 & & 55.79 & & 58.32 & \\
\hline \multicolumn{7}{|l|}{ Kick (max score 8) } \\
\hline Intervention & 7.71 & & 7.05 & & 7.63 & \\
\hline Control & 7.63 & & 6.58 & & 7.05 & \\
\hline \multicolumn{7}{|l|}{ Bounce (max score 8) } \\
\hline Intervention & 6.86 & & 7.28 & & 7.59 & \\
\hline Control & 6.73 & & 7.24 & & 7.74 & \\
\hline \multicolumn{7}{|l|}{ Catch (max score 6) } \\
\hline Intervention & 5.73 & & 5.68 & & 5.63 & \\
\hline Control & 5.71 & & 5.84 & & 5.61 & \\
\hline \multicolumn{7}{|l|}{ Strike (max score 10) } \\
\hline Intervention & 8.27 & & 8.45 & & 9.06 & \\
\hline Control & 8.79 & & 7.82 & & 8.87 & \\
\hline \multicolumn{7}{|l|}{ Overhand Throw (max score 8 ) } \\
\hline Intervention & 6.27 & & 2.89 & & 6.95 & \\
\hline Control & 6.76 & & 3.32 & & 6.87 & \\
\hline \multicolumn{7}{|l|}{ Underhand Roll (max score 8) } \\
\hline Intervention & 5.59 & & 6.03 & & 7.05 & \\
\hline Control & 6.11 & & 6.26 & & 6.71 & \\
\hline \multicolumn{7}{|l|}{ Balance (max score 10) } \\
\hline Intervention & 7.45 & & 7.45 & $n<05^{*}$ & 7.97 & \\
\hline Control & 7.76 & & 6.63 & & 7.63 & \\
\hline Object Control Subtest (max s & & & & & & \\
\hline Intervention & 40.42 & $p<.05^{*}$ & 37.38 & & 43.91 & \\
\hline Control & 41.74 & & 37.05 & & 42.84 & \\
\hline Total Gross Motor Skills (max & & & & & & \\
\hline Intervention & 98.94 & $n<05^{*}$ & 99.73 & & 110.39 & \\
\hline Control & 102.71 & & 99.47 & & 108.79 & \\
\hline
\end{tabular}


$p=.019)$ with a significantly greater increase occurring within the intervention school over time.

\section{Discussion}

The preliminary results from this pilot study suggest that it may be possible to increase 12 to 14 years old participation in daily MVPA within a one year time frame, through a collaborative, school-based PE intervention. In the present study, participants in the intervention school appeared to accumulate 7.2 minutes more daily MVPA (when measured by accelerometry) than participants in the control school at the retention phase of the intervention (see Table 1). Similar increases in PA reported from this study correspond to a previous school based intervention on adolescents after one year (Haerens et al., 2006), where female intervention participants accumulated 6.4 minutes more daily MVPA than those in the control group. Another recent study, by Kriemler et al. (2010) evaluating the effect of a school based PA programme on children found that intervention participants successfully obtained 11 more minutes of daily MVPA than control participants. Similar to previous interventions (Dishman et al., 2004; Jamner, Spruijt-Metz, Bassin, \& Cooper, 2004; McKenzie et al., 2004; Pate et al., 2005; Slootmaker, Chinapaw, Seidell, van Mechelen, \& Schuit, 2010), results of this study are comparable in that the Y-PATH multicomponent school-based PE intervention can contribute positively towards increasing and sustaining adolescent youth PA. There is now strong evidence under the behavioral and social approaches to increasing PA that school-based programmes are effective amongst children and adolescent youth (Garn et al., 2013; Lavelle et al., 2012; Salmon, Booth, Phongsavan, Murphy, \& Timperio, 2007; Vasques et al., 2013).

Due to the small number of participants with full objective accelerometer data, it was important to consider the self-report data to compliment MVPA findings. Consistent with previous studies (Prince et al., 2008; Slootmaker, Schuit, Chinapaw, Seidell, \& van Mechelen, 2009), the mean minutes of selfreport MVPA was substantially higher over time compared to the objective accelerometer findings (see Table 1). The original study hypothesis was that the intervention school participants would self-report greater MVPA over time, however, results showed no significant differences between groups. This is in contrast to other recent school based PA programmes, which highlighted significantly greater self-report minutes of MVPA at follow-up for those exposed to intervention conditions (Haerens et al., 2007; Taymoori et al., 2008). In terms of considering why the intervention school was not significantly more effective in the increase of self-report minutes of MVPA, it is important to note that children and youth (both intervention and control) often have difficulty accurately recalling PA participation (Hands et al., 2006; Townsend, 2012; Trost, 2007). In addition, a previous study by Trost et al. (2000) investigated children's (mean age $9.8 \pm .3$ years) understanding of PA, in which the results found that $60 \%$ of participants had difficulty in differentiating between sedentary activities and active pursuits. Based on this finding, it appears that young people may be unable to accurately quantify time spent in MVPA through selfreport. This may explain why no significant differences in selfreported MVPA existed between intervention and control group over time, and again emphasises the importance of using objective measures of PA where possible.

It is plausible that the greater self-reported minutes of daily
MVPA in the control group at follow-up may in part be attributed to the fact that, while both groups received the same amount of PE time ( 80 minutes) each week over the course of the school year, control participants received an additional 120 minutes "games class" per week for one school year (Sept 2011-May 2012). This additional 120 minutes of activity time was a specific school policy which was beyond the control of the research team. Yet despite this school policy, it is important to note that the control school did not self-report significantly higher MVPA over time compared to the intervention school, indicating that the intervention participants may have participated in more activity outside of school to "make-up" for the reduced activity time they were exposed to as part of their school PE curriculum.

Recent intervention results highlight a significant positive association between participation in school based movement skill programmes and FMS proficiency (Logan et al., 2011). FMS performance in a PE setting has previously found significant intervention effects for children and early adolescents (Kalaja et al., 2012; Lemos et al., 2012; Martin et al., 2009; Mitchell et al., 2013). Preliminary results from this pilot study are consistent with these FMS findings, indicating that adolescents exposed to a prescribed FMS climate during PE as part of the Y-PATH programme significantly improved in their overall movement skill proficiency relative to their control counterparts. It is particularly encouraging from a research perspective that these findings have emerged over the course of 12 months and even more so, when we consider that at baseline (pre-test), control school participants displayed significantly greater overall gross motor skill proficiency. Previous research highlights that younger children can achieve greater gains in motor skill proficiency (Mitchell et al., 2013) compared with older participants and hence, childhood is a critical period for FMS development (Gallahue \& Ozmun, 2006; Hardy et al., 2010; Lemos et al., 2012; Zask et al., 2012). Findings from this study suggest that adolescent youth aged 12 to 14 years old can significantly improve in FMS performance through a teacher led education intervention over one year. This finding is in line with other intervention programmes which have demonstrated significant improvements in FMS proficiency for children and adolescents through the school environment (Kalaja et al., 2012; Martin et al., 2009; Mitchell et al., 2013; Van Beurden et al., 2003). Such improvements in adolescent FMS proficiency are crucial to helping ensure a successful transition to more advanced skills in the specialized movement stage during adolescence (Department of Education Victoria, 1996; Gallahue \& Ozmun, 2006). The well informed opinion of Loitz (2013) suggests that the development of FMS during childhood and adolescence will help individuals to participate in PA and gain additional health benefits.

In light of this pilot study, it is important to consider that the effects of the intervention may be attributed to confounding factors other than the Y-PATH programme such as individual school characteristics or physical fitness levels etc. As both the control and intervention school had similar socio economic status (SES) and are situated in the same rural Irish setting, results of this study cannot be generalised without further research. For these reasons, the next stage of the Y-PATH research programme will undertake a definitive randomised controlled trial (RCT) in 22 mixed gender post-primary schools in September 2013. This robust surveillance of Y-PATH will precisely evaluate the overall intervention effectiveness for 
adolescent PA promotion.

\section{Study Limitations and Strengths}

Specific limitations of this study design were the use of two mixed-gender schools only, resulting in a small number of participants involved in the study. In terms of matching criteria, both schools were selected for inclusion based on geographical location and gender distribution; in terms of sample size, however, the control school was not an exact match to the intervention which is acknowledged as a limitation. The control school having an additional 120 minutes games class per week compared to the intervention school can similarly be viewed as a limitation. Further details regarding participant characteristics and measurement variables such as nutrition, body fatness and cardio-respiratory fitness level would have allowed the researchers to explore the effectiveness of the intervention more robustly. The stringent inclusion criteria for accelerometer analysis was applied in order to obtain a detailed, representative pattern of objectively measured habitual adolescent PA behavior but these research decisions had a significant adverse effect on the number of participants with available data for inclusion at each time point.

A unique aspect of this research was the involvement of all teaching staff, parents and guardians within this whole-school approach towards adolescent PA promotion in the Y-PATH programme. A novel component of Y-PATH was the integrative approach of HRA and FMS in the PE environment for adolescents. Intervention and control settings were matched based on gender and age distribution, furthermore, there were no differences in SES between participants. The use of accelerometry in conjunction with self-report questionnaire heightened the strength of PA measurement accuracy. Finally the measurement of 15 FMS will contribute significantly to the previously published literature in adolescent movement skill competency (Barnett et al., 2011; Barnett, Van Beurden, Morgan, Brooks, \& Beard, 2010; Hardy et al., 2010, 2013; Kalaja et al., 2012; Mitchell et al., 2013; Okely \& Booth, 2004).

\section{Conclusion}

In the wake of the positive objective PA findings over time in this study, preliminary findings advocate for the simultaneous integration of HRA and FMS in school PE class, along with parent and teacher involvement, in efforts to improve the overall PA levels of adolescent youth. Preliminary findings of the Y-PATH intervention suggest that adolescent FMS proficiency can significantly improve through a one-year-teacher-led intervention component. Recent evidence on the health benefits of FMS competency in children and adolescents (Lubans et al., 2010) found that 11 of the 13 identified studies indicated strong positive relationships between skill ability and PA components. Teaching children and young people during school PE classes to become competent and confident performers of FMS may lead to a greater willingness to participate in PA which in turn, may provide additional opportunities to improve physical fitness levels and reduce the risk of increased weight status (Barnett, Van Beurden, Morgan, Brooks, \& Beard, 2008; Cliff et al., 2011; Morano, Colella, \& Caroli, 2011). In light of the YPATH intervention, preliminary findings extend the knowledge on total PA participation among adolescents. Further longitudinal data are warranted to support these initial positive findings.

\section{Acknowledgements}

Research for the Y-PATH programme was supported by Dublin City University (Ireland), the Wicklow Local Sports Partnership (WLSP) and the Wicklow Vocational Education Committee (VEC). These funding contributors had no input in study design, in the collection, analysis and interpretation of data, in the writing of the report, or in the decision to submit the article for publication. We wish to acknowledge the trained field staff for their dedicated professionalism during each phase of data collection and analysis. Finally, a sincere gratitude to the participants, parents, teachers and principals from both of the post-primary schools involved.

\section{REFERENCES}

Aibar, A., Bois, J. E., Generelo, E., Zaragoza Casterad, J., \& Paillard, T. (2012). A cross-cultural study of adolescents' physiccal activity levels in France and Spain. European Journal of Sport Science, 1-8. http://dx.doi.org/10.1080/17461391.2012.746733

Anderson, C. B., Hagstromer, M., \& Yngve, A. (2005). Validation of the PDPAR as an adolescent diary: Effect of accelerometer cut points. Medicine \& Science in Sports \& Exercise, 37, 1224-1230.

http://dx.doi.org/10.1249/01.mss.0000170073.57440.df

Barnett, L. M., Morgan, P. J., Van Beurden, E., Ball, K., \& Lubans, D. R. (2011). A reverse pathway: Actual and perceived skill proficiency and physical activity. Medicine \& Science in Sports \& Exercise, 43, 898-904.

http://dx.doi.org/10.1249/MSS.0b013e3181fdfadd

Barnett, L. M., Van Beurden, E., Morgan, P. J., Brooks, L. O., \& Beard, J. R. (2008). Does childhood motor skill proficiency predict adolescent fitness? Medicine \& Science in Sports \& Exercise, 40, $2137-$ 2144. http://dx.doi.org/10.1249/MSS.0b013e31818160d3

Barnett, L. M., Van Beurden, E., Morgan, P. J., Brooks, L. O., \& Beard, J. R. (2009). Childhood motor skill proficiency as a predictor of adolescent physical activity. Journal of Adolescent Health, 44, 252-259. http://dx.doi.org/10.1016/j.jadohealth.2008.07.004

Barnett, L. M., Van Beurden, E., Morgan, P. J., Brooks, L. O., \& Beard, J. R. (2010). Gender differences in motor skill proficiency from childhood to adolescence: A longitudinal study. Research Quarterly for Exercise and Sport, 81, 162-170.

Belton, S., O’ Brien, W., Wickel, E. E., \& Issartel, J. (In Press). Patterns of Non-Compliance in Adolescent Field Based Accelerometer Research. Journal of Physical Activity \& Health.

Berkson, S. S., Espinola, J., Corso, K. A., Cabral, H., McGowan, R., \& Chomitz, V. R. (2013). Reliability of height and weight measurements collected by physical education teachers for a school-based body mass index surveillance and screening system. The Journal of School Health, 83, 21-27. http://dx.doi.org/10.1111/j.1746-1561.2012.00743.x

Booth, M. L., Okely, T., McLellan, L., Phongsavan, P., Macaskill, P., Patterson, J. et al. (1999). Mastery of fundamental motor skills among New South Wales school students: Prevalence and sociodemographic distribution. Journal of Science and Medicine in Sport, 2, 93-105.

Bouchard, C., Blair, S. N., \& Haskell, W. L. (2007). Physical activity and health. Champaign, IL: Human Kinetics.

Caspersen, C. J., Powell, K. E., \& Christenson, G. M. (1985). Physical activity, exercise, and physical fitness: Definitions and distinctions for health-related research. Public Health Reports, 100, 126-131.

Cavanagh, T., Macfarlane, A., Glynn, T., \& Macfarlane, S. (2012). Creating peaceful and effective schools through a culture of care. Discourse: Studies in the Cultural Politics of Education, 33, 443455 .

Cliff, D. P., Okely, A. D., Morgan, P. J., Steele, J. R., Jones, R. A., Colyvas, K., et al. (2011). Movement skills and physical activity in obese children: Randomized controlled trial. Medicine \& Science in Sports \& Exercise, 43, 90-100. http://dx.doi.org/10.1249/MSS.0b013e3181e741e8 
Cole, T. J., Bellizzi, M. C., Flegal, K. M., \& Dietz, W. H. (2000). Establishing a standard definition for child overweight and obesity worldwide: International survey. BMJ, 320, 1240-1243.

http://dx.doi.org/10.1136/bmj.320.7244.1240

Corder, K., Van Sluijs, E. M., Wright, A., Whincup, P., Wareham, N. J., \& Ekelund, U. (2009). Is it possible to assess free-living physical activity and energy expenditure in young people by self-report? American Journal of Clinical Nutrition, 89, 862870.

http://dx.doi.org/10.3945/ajen.2008.26739.862

Department of Education Victoria. (1996). Fundamental motor skills: A manual for classroom teachers. Melbourne, Australia.

Dishman, R. K., Motl, R. W., Saunders, R., Felton, G., Ward, D. S., Dowda, M., \& Pate, R. R. (2004). Self-efficacy partially mediates the effect of a school-based physical-activity intervention among adolescent girls. Preventive Medicine, 38, 628-636. http://dx.doi.org/10.1016/j.ypmed.2003.12.007

Eaton, D. K., Kann, L., Kinchen, S., Shanklin, S., Flint, K. H., Hawkins, J., et al. (2012). Youth risk behavior surveillance-United States, 2011. Morbidity and Mortality Weekly Report, 61, 1-162.

Esliger, D., Copeland, J., Barnes, J., \& Tremblay, M. (2005). Standardizing and optimizing the use of accelerometer data for free-living physical activity monitoring. Journal of Physical Activity \& Health, 3, 366-383.

Evenson, K. R., Catellier, D. J., Gill, K., Ondrak, K. S., \& McMurray, R. G. (2008). Calibration of two objective measures of physical activity for children. Journal of Sports Sciences, 26, 1557-1565. http://dx.doi.org/10.1080/02640410802334196

Gallahue, D. L., \& Ozmun, J. C. (2006). Understanding motor development: Infants, children, adolescents, adults (6th ed.). New York, NY: Mc-Graw Hill.

Garn, A. C., McCaughtry, N., Shen, B., Martin, J., \& Fahlman, M. (2013). Underserved adolescent girls' physical activity intentions and behaviors: Relationships with the motivational climate and perceived competence in physical education. Advances in Physical Education, 3, 103-110. http://dx.doi.org/10.4236/ape.2013.32018

Gorely, T., Nevill, M. E., Morris, J. G., Stensel, D. J., \& Nevill, A. (2009). Effect of a school-based intervention to promote healthy life-styles in 7 - 11 years old children. The International Journal of Behavioral Nutrition and Physical Activity, 6, 5. http://dx.doi.org/10.1186/1479-5868-6-5

Grasten, A., Watt, A., Jaakkola, T., \& Liukkonen, J. (2012). Directly measured and self-reported physical activity in a sample of Finnish secondary school students. Advances in Physical Education, 2, 132-138. http://dx.doi.org/10.4236/ape.2012.23023

Haerens, L., De Bourdeaudhuij, I., Maes, L., Cardon, G., \& Deforche, B. (2007). School-based randomized controlled trial of a physical activity intervention among adolescents. The Journal of Adolescent Health, 40, 258-265.

http://dx.doi.org/10.1016/j.jadohealth.2006.09.028

Haerens, L., Deforche, B., Maes, L., Cardon, G., Stevens, V., \& De Bourdeaudhuij, I. (2006). Evaluation of a 2-year physical activity and healthy eating intervention in middle school children. Health Education Research, 21, 911-921. http://dx.doi.org/10.1093/her/cyl115

Hardy, L., King, L., Espinel, P., Cosgrove, C., \& Bauman, A., (2010). NSW schools physical activity and nutrition survey (SPANS). Full Report. Sydney: NSW Ministry of Health.

Hardy, L., Barnett, L., Espinel, P., \& Okely, A. D. (2013). Thirteen-year trends in child and adolescent fundamental movement skills: 1997-2010. Medicine \& Science in Sports \& Exercise, (Published ahead of Print). http://dx.doi.org/10.1249/MSS.0b013e3181ac7a45

Jamner, M. S., Spruijt-Metz, D., Bassin, S., \& Cooper, D. M. (2004). A controlled evaluation of a school-based intervention to promote physical activity among sedentary adolescent females: Project FAB. The Journal of Adolescent Health, 34, 279-289. http://dx.doi.org/10.1016/j.jadohealth.2003.06.003

Kahn, E. B., Ramsey, L. T., Brownson, R. C., Heath, G. W., Howze, E. H., Powell, K. E., et al. (2002). The effectiveness of interventions to increase physical activity: A systematic review. American Journal of Preventive Medicine, 22, 73-107.
Kalaja, S. P., Jaakkola, T. T., Liukkonen, J. O., \& Digelidis, N. (2012). Development of junior high school students' fundamental movement skills and physical activity in a naturalistic physiccal education setting. Physical Education and Sport Pedagogy, 17, 411-428.

Kimm, S. Y., Glynn, N. W., Kriska, A. M., Fitzgerald, S. L., Aaron, D. J., Similo, S. L., et al. (2000). Longitudinal changes in physical activity in a biracial cohort during adolescence. Medicine \& Science in Sports \& Exercise, 32, 1445-1454.

Kriemler, S., Zahner, L., Schindler, C., Meyer, U., Hartmann, T., Hebestreit, H., et al. (2010). Effect of school based physical activity programme (KISS) on fitness and adiposity in primary schoolchildren: Cluster randomised controlled trial. BMJ, 340, 1-8. http://dx.doi.org/10.1136/bmj.c785

Lavelle, H. V, Mackay, D. F., \& Pell, J. P. (2012). Systematic review and meta-analysis of school-based interventions to reduce body mass index. Journal of Public Health, 34, 360-369. http://dx.doi.org/10.1093/pubmed/fdr116

Logan, S. W., Robinson, L. E., Wilson, A. E., \& Lucas, W. A. (2011). Getting the fundamentals of movement: A meta-analysis of the effectiveness of motor skill interventions in children. Child: Care, Health and Development, 38, 305-315. http://dx.doi.org/10.1111/j.1365-2214.2011.01307.x

Loitz, C. (2013). The importance of lifelong physical literacy. Alberta Centre for Active Living-Research and Education for the Promotion of Physical Activity. Well Spring: Sharing Physical Activity Knowledge 24.

Lubans, D. R., Morgan, P. J., Cliff, D. P., Barnett, L. M., \& Okely, A. D. (2010). Fundamental movement skills in children and adolescents: Review of associated health benefits. Sports Medicine, 40, 1019 1035. http://dx.doi.org/10.2165/11536850-000000000-00000

Martin, E. H., Rudisill, M. E., \& Hastie, P. A. (2009). Motivational climate and fundamental motor skill performance in a naturalistic physical education setting. Physical Education \& Sport Pedagogy, 14, 227-240. http://dx.doi.org/10.1080/17408980801974952

May, A. L., Kuklina, E. V, \& Yoon, P. W. (2012). Prevalence of cardiovascular disease risk factors among US adolescents, 1999-2008. Pediatrics, 129, 1035-1041. http://dx.doi.org/10.1542/peds.2011-1082

McKenzie, T. L., \& Lounsbery, M. A. F. (2009). School physical education: The pill not taken. American Journal of Lifestyle Medicine, 3, 219-225. http://dx.doi.org/10.1177/1559827609331562

McKenzie, T. L., Sallis, J. F., Prochaska, J. J., Conway, T. L., Marshall, S. J., \& Rosengard, P. (2004). Evaluation of a two-year middleschool physical education intervention: M-SPAN. Medicine \& Science in Sports \& Exercise, 36, 1382-1388. http://dx.doi.org/10.1249/01.MSS.0000135792.20358.4D

Mitchell, B., McLennan, S., Latimer, K., Graham, D., Gilmore, J., \& Rush, E. (2013). Improvement of fundamental movement skills through support and mentorship of class room teachers. Obesity Research \& Clinical Practice, 7, e230-e234. http://dx.doi.org/10.1016/j.orcp.2011.11.002

Morano, M., Colella, D., \& Caroli, M. (2011). Gross motor skill performance in a sample of overweight and non-overweight preschool children. International Journal of Pediatric Obesity, 6, 42-46. http://dx.doi.org/10.3109/17477166.2011.613665

Nyberg, G., Ekelund, U., \& Marcus, C. (2009). Physical activity in children measured by accelerometry: Stability over time. Scandinavian Journal of Medicine \& Science in Sports, 19, 30-35. http://dx.doi.org/10.1111/j.1600-0838.2007.00756.x

O’Donovan, G., Blazevich, A. J., Boreham, C., Cooper, A. R., Crank, H., Ekelund, U., et al. (2010). The ABC of physical activity for health: A consensus statement from the British association of sport and exercise sciences. Journal of Sports Sciences, 28, 573-591. http://dx.doi.org/10.1080/02640411003671212

Okely, A. D, Booth, M. L., \& Patterson, J. W. (2001). Relationship of physical activity to fundamental movement skills among adolescents. Medicine \& Science in Sports \& Exercise, 33, 1899-1904. http://dx.doi.org/10.1097/00005768-200111000-00015

Okely, A. D, \& Booth, M. L. (2004). Mastery of fundamental movement skills among children in New South Wales: Prevalence and sociodemographic distribution. Journal of Science and Medicine in 
Sport, 7, 358-372.

http://dx.doi.org/10.1016/S1440-2440(04)80031-8

Pate, R. R., Ward, D. S., Saunders, R. P., Felton, G., Dishman, R. K., \& Dowda, M. (2005). Promotion of physical activity among highschool girls: A randomized controlled trial. American Journal of Public Health, 95, 1582-1587. http://dx.doi.org/10.2105/AJPH.2004.045807

Payne, V. G., \& Morrow, J. R. J. (2009). School physical education as a viable change agent to increase youth physical activity. The President's Council on Physical Fitness and Sports Research Digest, 10, 1-8.

Perry, C. K., Garside, H., Morones, S., \& Hayman, L. L. (2012). Physical activity interventions for adolescents: An ecological perspective. The Journal of Primary Prevention, 33, 111-135. http://dx.doi.org/10.1007/s10935-012-0270-3

Physical Activity Guidelines Advisory Committee. (2008). Physical activity guidelines advisory committee report, 2008. Washington DC: Department of Health and Human Services.

Physical Activity Guidelines Advisory Committee of the President's Council on Fitness, Sports \& Nutrition (2012). Physical activity guidelines for Americans mid-course report: Strategies to increase physical activity among youth. Washington DC: Department of Health and Human Services.

Prince, S. A., Adamo, K. B., Hamel, M. E., Hardt, J., Gorber, S. C., \& Tremblay, M. (2008). A comparison of direct versus selfreport measures for assessing physical activity in adults: A systematic review. The International Journal of Behavioral Nutrition and Physical Activity, 5, 56. http://dx.doi.org/10.1186/1479-5868-5-56

Sallis, J. F., McKenzie, T. L., Beets, M. W., Beighle, A., Erwin, H., \& Lee, S. (2012). Physical education's role in public health: Steps forward and backward over 20 years and HOPE for the future. Research Quarterly for Exercise and Sport, 83, 125-135.

Salmon, J., Booth, M. L., Phongsavan, P., Murphy, N., \& Timperio, A. (2007). Promoting physical activity participation among children and adolescents. Epidemiologic Reviews, 29, 144-159. http://dx.doi.org/10.1093/epirev/mxm010

Scheerder, J., Vanreusel, B., Beunen, G., Claessens, A., Renson, R., Thomis, M., et al. (2008). Lifetime adherence to sport and physical activity as a goal in physical education. In J. Seghers, \& H. Vangrunderbeek (Eds.), Physical Education Research What's the Evidence. Leuven: Utigeverij Acco.

Sibbald, B., \& Roland, M. (1998). Understanding controlled trials: Why are randomised controlled trials important? BMJ, 316, 201.

Slootmaker, S. M., Chinapaw, M. J. M., Seidell, J. C., Van Mechelen, W., \& Schuit, A. J. (2010). Accelerometers and internet for physical activity promotion in youth? Feasibility and effectiveness of a minimal intervention. Preventive Medicine, 51, 31-36.

http://dx.doi.org/10.1016/j.ypmed.2010.03.015

Slootmaker, S. M., Schuit, A. J., Chinapaw, M. J., Seidell, J. C., \& Van Mechelen, W. (2009). Disagreement in physical activity assessed by accelerometer and self-report in subgroups of age, gender, education and weight status. The International Journal of Behavioral Nutrition and Physical Activity, 6, 17.

http://dx.doi.org/10.1186/1479-5868-6-17

Taymoori, P., Niknami, S., Berry, T., Lubans, D., Ghofranipour, F., \& Kazemnejad, A. (2008). A school-based randomized controlled trial to improve physical activity among Iranian high school girls. The International Journal of Behavioral Nutrition and Physical Activity, 5, 1-13. http://dx.doi.org/10.1186/1479-5868-5-18

Telama, R. (2009). Tracking of physical activity from childhood to adulthood: A review. Obesity Facts, 2, 187-195. http://dx.doi.org/10.1159/000222244

Telama, R., Yang, X., Viikari, J., Välimäki, I., Wanne, O., \& Raitakari, O. (2005). Physical activity from childhood to adulthood: A 21-year tracking study. American Journal of Preventive Medicine, 28, $267-$ 273. http://dx.doi.org/10.1016/j.amepre.2004.12.003

Ulrich, D. A. (1985). Test of gross motor development. TX: PRO-ED.

Ulrich, D. A. (2000). Test of gross motor development 2: Examiner's manual (2nd ed.). Austin, TX: PRO-ED.

Van Beurden, E., Barnett, L., Zask, A., Dietrich, U., Brooks, L., \& Beard, J. (2003). Can we skill and activate children through primary school physical education lessons: "Move it groove it" - a collaborative health promotion intervention. Preventive Medicine, 36, 493-501. http://dx.doi.org/10.1016/S0091-7435(02)00044-0

Van Sluijs, E. M. F., McMinn, A. M., \& Griffin, S. J. (2008). Effectiveness of interventions to promote physical activity in children and adolescents: Systematic review of controlled trials. British Journal of Sports Medicine, 42, 653-657.

Vasques, C., Magalhaes, P., Cortinhas, A., Mota, P., Leitao, J., \& Lopes, V. P. (In Press). Effects of intervention programs on child and adolescent BMI: A meta-analysis study. Journal of Physical Activity \& Health.

Ward, D. S., Saunders, R. P., \& Pate, R. R. (2007). Physical activity interventions in children and adolescents. Champaign, IL: Human Kinetics.

Wichstrøm, L., Von Soest, T., \& Kvalem, I. L. (2012). Predictors of growth and decline in leisure time physical activity from adolescence to adulthood. Health Psychology, 32, 775-784.

Woods, C. B., Tannehill, D., Quinlan, A., Moyna, N., \& Walsh, J. (2010). The children's sport participation and physical activity study (CSPPA). Research Report No 1, Dublin.

Yildirim, M., Verloigne, M., De Bourdeaudhuij, I., Androutsos, O., Manios, Y., Felso, R., et al. (2011). Study protocol of physical activity and sedentary behaviour measurement among schoolchildren by accelerometry: Cross-sectional survey as part of the ENERGY-project. BMC Public Health, 11, 1-7. http://dx.doi.org/10.1186/1471-2458-11-182

Zask, A., Barnett, L. M., Rose, L., Brooks, L. O., Molyneux, M., Hughes, D., et al. (2012). Three year follow-up of an early childhood intervention: Is movement skill sustained? The International Journal of Behavioral Nutrition and Physical Activity, 9, 1-9. http://dx.doi.org/10.1186/1479-5868-9-127 